\title{
ESPAÇOS EDUCATIVOS IMPULSIONADORES DA EDUCAÇÃO AMBIENTAL
}

\author{
Hedy Silva Ramos de Vasconcellos* \\ Maria de Lourdes Spazziani* \\ Antonio Fernando Silveira Guerra \\ João Batista de Albuquerque Figueiredo ${ }^{* * * *}$
}

RESUMO: A educação ambiental (EA) vem-se expandindo no Brasil em diversos espaços educativos formais e não-formais. Este texto considera a EA provocadora de mudanças políticas, estimuladora de uma racionalidade ética e ecológica e promovedora de atitudes e valores pessoais e de práticas sociais compatíveis com a sustentabilidade da vida na Terra. Sob esta visão, o artigo tem como objetivo refletir sobre a expansão da educação ambiental nas universidades brasileiras, nos últimos vinte anos; discutir as possíveis mudanças educacionais das políticas públicas da área, a partir da Constituição de 1988; considerar a possível influência das forças dos movimentos sociais da sociedade organizada e das redes de EA locais, regionais e nacionais formadas com a generalização do uso da informática, como impulsionadora da sua expansão. A EA se constitui e se formaliza com o respaldo de uma política nacional que propicia sua permanência e aprofundamento

* Doutora em Educação e professora da Pontifícia Universidade Católica do Rio de Janeiro (PUC-RJ).E-mail: hedy@edu.puc-rio.br

** Doutora em Educação e professora da Universidade Estadual Paulista Júlio de Mesquita Filho (UNESP).E-mail: spazziani@ibb.unesp.br

*** Doutor em Engenharia de Produção e professor do Programa de Pós-Graduação em Educação e do Núcleo das Licenciaturas da Universidade do Vale do Itajaí (Univali). E-mail: guerra@univali.br

**** Doutor em Educação Ambiental e professor da Faculdade de Educação e do Programa de Pós-Graduação em Educação da Universidade Federal do Ceará (UFC). E-mail: joao.figueiredo@pq.cnpq.br 
nos espaços já conquistados e promove sua inserção nos demais contextos da sociedade organizada.

Palavras-chave: Educação ambiental. Universidade. Políticas públicas. Redes. Movimentos sociais.

\section{EdUCATIVE PLACES FOR ENVIRONMENTAL EDUCATION ENCOURAGEMENT}

ABSTRACT: Environmental education (EE) has expanded in Brazil in diverse educational settings, both formal and non-formal. This text considers EE as provoking political change, stimulating an ethical and ecological rationality and promoting personal values and attitudes, as well as social practices, compatible with the sustainability of life on earth. From this perspective, the principal objective of the article is to reflect on the expansion of environmental education in Brazilian universities in the last twenty years; discuss the changes in public educational policies, since the 1988 constitution; and to consider the possible influence of social movements in organized society, as well as the networks of local, regional and national $\mathrm{EE}$, together with the generalized use of computer technology, as impulses in its expansion. Environmental education constitutes and formalizes itself as a foundation for national policies that contribute to its permanence and deepening in the spaces where it already exists and promotes its inclusion in the other contexts of organized society.

Key words: Environmental education. University. Public policies. Networks. Social movements.

\section{Introdução}

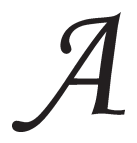

educação ambiental (EA) vem-se expandindo, no Brasil, nesses últimos vinte anos, em diversos espaços educativos, formais e não-formais. Destacaremos como espaços educativos importantes: as universidades, por serem geradoras de profissionais da Educação; as políticas públicas educativas para a área, por serem espaços de consolidação e formalização de ações do contexto social; as redes de EA, por sua representação como movimento social inovador, em especial para a área enfocada; os movimentos sociais, especialmente o da educação popular, contribuindo com a expressão de novos valores ansiados pelos educadores e educadoras ambientais inseridos nos diferentes micro-contextos sociais desse nosso imenso país. 
A importância das universidades brasileiras pode ser estudada sob o ponto de vista da valorização dos estudos ambientais nos seus diferentes campos: das ciências biológicas ao tecnológico, como na engenharia ambiental; social, como no direito ambiental e na análise de impactos sobre o meio ambiente; no campo das ciências humanas, onde se situa a educação. É porque, ao se falar da educação, estamos falando também da formação em todos os outros setores profissionais em que temos que considerar a necessidade da ambientalização curricular, ${ }^{1}$ isto é, que a EA seja o modo de se educar, nos diferentes campos científicos. Por isso, a EA na universidade é tida como impulsionadora da expansão desta nova visão educacional, embora tenhamos clareza da complexidade das ações conjuntas sobre esse fenômeno.

No que se refere à EA nas políticas públicas educativas, identificamos diversas incorporações, na legislação, por instâncias do governo federal e a emergência timidamente articulada entre os órgãos educativos e ambientais até fins da década de 1990 . No caso das redes de educação ambiental e dos movimentos sociais, embora cientes do papel de vanguarda dos movimentos ambientalistas para a emergência da educação ambiental em toda a rede societária atual, evidenciamos a importância das redes de EA na capilarização da EA e contribuições efetivas frente ao contexto, muitas vezes adversos, das propostas nas políticas públicas.

No caso dos movimentos advindos da educação popular, destacamos aqui a incorporação da educação ambiental nos movimentos da educação popular, sendo influenciada principalmente pelos ideais educativos de Paulo Freire como propositora de novas formas do educar socioambientalmente.

A expansão da educação ambiental nas universidades brasileiras

A constatação das consequências da utilização pelo mundo globalizado do avanço científico/tecnológico planejado, sem levar em conta as alterações que poderiam causar sobre o meio ambiente, a sociedade e o planeta, como um todo, provocou uma inquietude mundial, na segunda metade do século Xx. Após estudos específicos, como o que gerou o Relatório "Limites do Crescimento", foram realizadas diversas reuniões internacionais, iniciadas em 1972, promovidas pela Organização das Nações Unidas (ONU). A "Declaração da ONU sobre o meio 
ambiente humano", de Estocolmo, fruto deste encontro de governantes, embora de cunho político e econômico, afirma, literalmente, ser "indispensável um trabalho de educação em questôes ambientais" (Dias, 2004, p. 372).

Enquanto países industrializados do hemisfério norte do planeta já se preocupavam com a EA, mesmo antes da Reunião da ONU - como os Estados Unidos que, em 1970, aprovaram uma Lei sobre Educação Ambiental (idem, ibid., p. 34) - pode-se dizer que o trabalho educativo, nesta época, no Brasil, voltava-se mais para a expansão quantitativa do sistema educacional, com uma proposta política de desenvolvimento econômico e científico/tecnológico. Apenas algumas pessoas, chamadas de fundadores por Carvalho (2001), na década de 1970, eram visualizadas como ambientalistas, preocupadas e atuando no meio ambiente, por considerá-lo um patrimônio da humanidade. Era um grupo voltado para movimentos sociais de cunho político, praticados pelas organizações nãogovernamentais (ONGs) ambientalistas. Os movimentos sociais de cunho educacional, entre nós, desde o início da segunda metade do século XX, preocupavam-se em combater o analfabetismo em adultos e conseguir mais escolas de melhor qualidade para os pobres, na chamada educação popular. Só nos anos de 1990, esses dois movimentos vão se aproximar, visivelmente. É com essa aproximação que surgirão as práticas não-formais de EA.

O ambientalismo, assim, desenvolve-se, no Brasil, antes de influenciar a educação brasileira. Nas escolas, apenas em poemas (como "O pássaro cativo" ou "Canção do exílio"), histórias, lendas e canções, tentava-se despertar, especialmente as crianças, para a necessidade de preservação da fauna e flora do país, sensibilizando-as pela emoção, principalmente, desde o século XIX. No entanto, a EA é uma educação política que se apóia em uma visão de mundo complexa e, por isso, é muito mais do que sensibilização, embora também a envolva.

Entretanto, os movimentos sociais se expandem nos anos 1980, em diversas regiões brasileiras, tendo as características pluriclassistas típicas dos que eram considerados os "novos movimentos sociais" (Boschi, 1987), envolvendo professores universitários. O engajamento das universidades com a educação popular, principalmente através das atividades de extensão (Vasconcellos, 1991) e com a EA nos seminários e congressos que vão sendo organizados, vai repercutir na produção acadêmica dos 
cursos stricto sensu em expansão, desde a Reforma Universitária de 1968 (Brasil, 1968).

Como resultado, são produzidas as primeiras dissertações de mestrado e teses de doutorado em EA na década de 1980 (Alves, 2006). Os trabalhos, na década de 1990, sofrem grande influência da Conferência das Naçôes Unidas sobre o Meio Ambiente e Desenvolvimento (CNUMAD), realizada pela ONU em 1992, na cidade do Rio de Janeiro, que aprovou a Agenda 21, em que a EA aparece, em destaque, na Seção IV. O chamado Fórum Internacional, movimento paralelo realizado por grande número de ONGs, propõe o Tratado de Educação Ambiental para Sociedades Sustentáveis e Responsabilidade Global, em que a EA é um processo em permanente construção.

(...) a educação ambiental para uma sustentabilidade equitativa é um processo de aprendizagem permanente, baseado no respeito a todas as formas de vida. Tal educação afirma valores e ações que contribuem para a transformação humana e social e para a preservação ecológica. Ela estimula a formação de sociedades socialmente justas e ecologicamente equilibradas, que conservem entre si a relação de interdependência e diversidade. Isto requer responsabilidades individual e coletiva no nível local, nacional e planetário. (Fórum Internacional das ONGs, 1992, p. 193-4)

No entanto, este processo vai se manifestar, de fato, nos anos 2000, nas diversas reformulações do Programa Nacional de Educação Ambiental (PRONEA). Na época, inicia-se também a formação da Rede Brasileira de Educação Ambiental (REBEA), concretizando a fusão dos dois movimentos sociais. No entanto, este processo vai se manifestar, de fato, nos anos 2000, nas duas versões do Programa Nacional de Educação Ambiental (PRONEA): uma em 1997 e, outra, reformulada em consulta pública nacional realizada em 2004.

A participação dos professores universitários nos movimentos da sociedade civil organizada gera, como frutos, uma explosão na produção discente do mestrado e do doutorado dos anos de 1990. Isso começa a ser percebido por docentes de programas de pós-graduação, relacionados à EA (Vasconcellos, 1999) e ao ensino de Ciências (Megid Neto, 1998). Notou-se também que ocorria uma dispersão de orientadores, como no estudo feito por Vasconcellos, que analisou o resumo de 59 trabalhos de mestrado e doutorado. Quem tinha orientado mais 
dissertações ou teses tinha tido oito orientados, até 1998, situação que continuou, em contagem mais ampla, ocorrendo nas três últimas décadas (Alves, 2006).

O Banco de Teses da CAPES, consultado por Alves (2006), indica um total de seis dissertações de mestrado nos anos de 1988 e 1989 e, na década seguinte, ocorre uma multiplicação geométrica. Este número passou para 223 dissertaçóes de mestrado e 20 teses de doutorado, de 1990 a 1999 . Na década atual, foram contadas, pela autora acima citada, 627 dissertações e 65 teses, como total dos anos 2000 a 2004. Ainda são registradas 39 dissertações de mestrado profissional, no Banco de Teses citado. Contudo, a tendência da dispersão observada se mantém, tal como registrada na obra de Alves, acima referida: que o orientador com o maior número de orientaçôes somava 20 trabalhos orientados, no total de 980 trabalhos registrados. O número de professores universitários que haviam orientado apenas uma dissertação ou tese foi de $70 \%$.

A forma pela qual são desenvolvidos esses estudos e como analisam o processo e o produto da EA brasileira é tema importante para o acompanhamento da sua expansão e aperfeiçoamento.

\section{Das intenções à inserção da educação ambiental nas políticas públicas brasileiras}

No Brasil, a EA nas políticas públicas federais é marcada por iniciativa do Poder Executivo, com a criação, em 1973, da antiga Secretaria do Meio Ambiente (SEMA), vinculada ao Ministério do Interior. Esta Secretaria assume, entre outras funções, esclarecer e educar a sociedade brasileira, tendo em vista o uso adequado dos recursos naturais e a conservação do meio ambiente (Brasil, 2005).

Sem pretender enumerar todas as iniciativas relacionadas à EA pelos setores públicos, identifica-se que, nos documentos que tratam do histórico dessa área, as ações convergem, especialmente, para a inserção desta temática nos currículos escolares da educação básica, à formação de professores, produção de material didático e a promoção de encontros e seminários (Brasil, 2005).

O Ministério da Educação e do Desporto (MEC) propõe sua inclusão no ensino formal. ${ }^{2}$ No entanto, podemos afirmar que são iniciativas 
Hedy S. Vasconcellos, Maria L. Spazziani, Antonio F. Guerra \& João B. Figueiredo

tímidas se comparadas ao que sucede a partir de sua explicitação no texto constitucional.

A Constituição Brasileira de 1988, ao incorporar demandas das sociedades contemporâneas atuais, especialmente no que se refere às áreas de conflitos relacionadas ao uso dos recursos naturais e a certos aspectos do desenvolvimento urbano, dedica o artigo 225, do capítulo VI, para a tutela do meio ambiente pelo governo brasileiro, com o seguinte texto: "Todos têm direito ao meio ambiente ecologicamente equilibrado, bem de uso comum do povo e essencial à sadia qualidade de vida, impondo-se ao poder público e à coletividade o dever de defendê-lo e preservá-lo para as presentes e futuras geraçōes" (Brasil, 1988).

Esse documento, além de consagrar a conservação do meio ambiente, anteriormente protegido somente no âmbito infraconstitucional, destaca a necessidade da União, estados, municípios e Distrito Federal "promover a educação ambiental em todos os níveis de ensino e a conscientização pública para a preservação do meio ambiente" (idem, $\$ 1^{\circ}, \mathrm{VI}$ ), principalmente junto às administrações públicas. Assim, responde aos preceitos das conferências e protocolos mundiais e aos movimentos iniciais do MEC e da SEMA.

Nesse período pós-constitucional, em 1991, no MEC, é criado um grupo de trabalho para implantação da educação ambiental no contexto escolar, em todo o país, que posteriormente constitui a Coordenadoria de Educação Ambiental (COEA).

Essa coordenadoria tem papel fundamental no desenvolvimento da política de EA, pois promove parcerias com o Instituto Brasileiro de Meio Ambiente (IBAMA), ${ }^{3}$ a fim de discutir diretrizes que irão definir a política da EA.

A COEA, inserida na Secretaria de Ensino Fundamental do MEC, desenvolve os Parâmetros Curriculares Nacionais (PCN), no que se refere ao tema transversal "meio ambiente" do currículo do ensino fundamental (Brasil, 1997). Os PCN assumem o termo "meio ambiente" como centralidade desse tema transversal. No entanto, o termo educação ambiental, desde a Conferência de Estocolmo (1972), esteve associado à formação ou reeducação de pessoas, por meio da criação de novas formas de percepção, promotora de relações sustentáveis e consequente melhoria da qualidade da vida humana e não-humana. Entretanto, "meio ambiente", além de ser uma representação social, é compreendido 
como aspectos físicos naturais e culturais e limita-se à materialidade do termo a que se refere (Castro, Spazziani \& Pedrosa, 2002).

Ainda no ano de 1992, foram criados o Ministério do Meio Ambiente (MMA) e o Instituto Brasileiro do Meio Ambiente (IBAMA), mas a constituição do Grupo de Trabalho de Educação Ambiental aconteceu em 1996. Intensificam-se articulaçōes entre o MEC e o MMA, que assinam protocolo de intenções para açōes conjuntas (Brasil, 2005).

A educação ambiental fortaleceu-se com a criação da Diretoria de Educação Ambiental (DEA), quando foi sancionada a Lei n. 9.795, em 27 de abril de 1999. Esta Lei, que dispõe sobre a Política Nacional de Educação Ambiental (PNEA), reconhece esta área como um componente urgente, essencial e permanente em todo processo educativo, formal e/ou não-formal, como orientam os artigos 205 e 225 da Constituição Federal de 1988.

No entanto, as proposições de gestão articulada da EA entre os dois ministérios formalizaram-se apenas em julho de 2002, quando a PNEA foi regulamentada pelo Decreto n. 4.281, que definiu, entre outras ações, a composição e as competências de seu órgão gestor. No MMA, a Diretoria de Educação Ambiental (DEA), criada em 1999, reafirma o papel deste Ministério para o desenvolvimento da EA no novo contexto político. No MEC, por outro lado, há recrudescimento das ações, até então lideradas pela COEA, quando o ministro da Educação Cristovam Buarque destitui esta coordenadoria. A pressão das redes de EA, bem como da sociedade civil organizada e de outros grupos associados, promove a suspensão dessa medida ministerial.

A EA é reestruturada nos dois ministérios. A COEA sai da Secretaria de Ensino Fundamental (SEF) e é instalada na Secretaria de Educação Continuada, Alfabetização e Diversidade (SECAD) como Coordenação Geral de Educação Ambiental (CGEA). Em princípio, pode-se compreender esta estruturação como um ganho para a EA no interior do MEC, que pode estender-se para outros níveis de ensino. $\mathrm{Na}$ DEA/ MMA busca-se a integração entre as diversas secretarias e órgãos vinculados do MMA (Brasil, 2006).

Entretanto, a instalação do órgão gestor da PNEA, já prevista na lei, aconteceu apenas em 2003. Este órgão é dirigido pela DEA/MMA e pela COEA/MEC, com assessoramento de um Comitê Assessor formado por instituições governamentais e da sociedade civil. 
No período de 2003-2006, o órgão gestor da PNEA destaca que as ações da DEA envolvem a formação em educação ambiental de educadores populares e "assuntos relativos à comunicação ambiental com caráter educador". Já a CGEA se expressa por meio do Programa "Vamos cuidar do Brasil com as escolas" e procura viabilizar políticas públicas para o sistema formal de ensino (Brasil, 2006). Ainda neste período, foram desenvolvidos 17 projetos ou programas. Deste total, três são liderados explicitamente pela CGEA e nove deles têm a frente o atualmente denominado Departamento de Educação Ambiental (DEA) (Brasil, 2006).

Constata-se que a EA, no espaço da política pública nacional, concretiza e formaliza articulações iniciadas, há décadas, entre os dois ministérios. Há permanência dos programas de formação de educadores, criam-se novas estruturas para o desenvolvimento da EA, há incremento de publicações para a área e apoio para eventos relacionados à EA.

A idéia de EA emerge nas sociedades atuais do interior do movimento ambientalista, mas no espaço das políticas públicas ela precisa ser reconhecida e recomendada para tornar-se parte essencial da educação de todos os cidadãos. Assim, espera-se que esses programas e projetos contribuam efetivamente para que atitudes e conceitos sustentáveis sobre as relaçôes do ser humano com ambiente natural e cultural sejam apropriados e internalizados no contexto de ações locais desenvolvidas por todos os atores da sociedade brasileira.

A parceria das redes na implementação de políticas públicas para educação ambiental

A organização em redes pode ser uma alternativa diferenciada e promissora de gestão e organização social. Ao contrário das redes organizacionais que conhecemos (redes de comunicação, supermercados, lojas e empresas), na rede social não existe predomínio de concentração de poder ou sua hierarquização, porque a ocorrência sistemática e permanente de processos de autorregulação no interior da rede garante que diferentes atores criem soluçóes emergentes para garantir a sobrevivência, a expansão ou a ampliação do conjunto (Capra, 1996). Assim, uma rede pode contribuir para a expansão de relações entre seus membros através das informaçôes veiculadas, das trocas interpessoais em diversos níveis e dos processos de mobilização (Lima, 2006). 
A idéia de rede implica admitir a complexidade do social, composta de setores e agrupamentos sociais heterogêneos, campos de múltiplas contradiçôes, diversidades e discursos plurais, em que opera não apenas a lógica do conflito, mas também da cooperação e da solidariedade. (Scherer-Warren, 1999, p. 50-51)

Transpondo essas condições básicas e adequando-as à organização das redes sociais, particularmente, das redes de EA, estas se fundamentam em alguns princípios da cultura de redes como: padrão organizacional horizontal, ausência de hierarquias, conectividade, não-linearidade, descentralização do poder, dinamismo organizacional (Martinho, 2004), entre outros. Entre seus elos, criam-se laços de relacionamento e parceria, sendo a circulação rápida das informaçôes e a comunicação, sem barreiras formais ou hierárquicas, um aspecto fundamental.

A constituição de redes de EA brasileiras tem importante papel na implementação das políticas públicas no campo ambiental. Elas caracterizam-se pelo seu potencial de interatividade e pela democratização da informação, da cultura, do conhecimento, de inclusão social, emancipação política e do exercício da cidadania responsável. Apresentam uma história de organização bastante diversificada, que revela pontos interessantes da tessitura de cada uma. As distinções entre essas categorias são níveis de responsabilidades diferentes em sua manutenção e administração (Guerra et al., 2007).

As redes de EA brasileiras tecem a chamada rede das redes, a Rede Brasileira de Educação Ambiental (REBEA), ${ }^{4}$ articulando e fortalecendo a atuação de educadores e educadoras ambientais no Brasil (Guerra, 2004).

Ao se organizar segundo os princípios da cultura de redes, seus membros fortalecem suas ações e, com isso, podem influir decisivamente na discussão das questões ambientais e nas políticas públicas para o setor.

Após a realização do V Fórum Brasileiro de Educação Ambiental, em 2004, e do encontro no V Congresso Ibero-americano de EA, em 2006, a organização de redes de EA, como espaços de articulação e interlocução, vem aumentando, principalmente por permitir uma rápida articulação e interação entre pessoas, com objetivos comuns, propiciando a discussão de princípios que vão do diálogo de saberes à convivência entre as diversidades. 
Constituindo uma alternativa de comunicação, informação e transformação cultural, que rompe com os padrões organizacionais hierárquicos das redes tradicionais, as redes sociais são comunidades de relações que, por meio dos recursos virtuais das tecnologias, bem como de encontros presenciais regionais e nacionais, aproximam pessoas politicamente comprometidas com a dimensão política da educação e a defesa da vida, o que as torna capazes de se unir em torno de objetivos comuns, uma idéia-força (Inojosa, 1999). Dessa forma, as redes tornam-se meios abrangentes de mobilização, sensibilização e informação para a participação individual e coletiva, visando atingir as finalidades de uma EA crítica e emancipadora (Loureiro et al., 2000).

O trabalho de articulação política das redes tem sido reconhecido pelos gestores das políticas públicas nos estados e no governo federal. A REBEA participa do Comitê Assessor do órgão gestor da PNEA. A REASUL, por exemplo, desde 2004, integra a Comissão Interinstitucional de EA (CIEA-SC) como membro da sociedade civil, juntamente com mais quatro instituições-elo da rede.

As redes de EA, no Brasil, por intermédio de seus elos, membros e facilitadores, têm promovido a articulação com a agenda do órgão gestor da PNEA no enraizamento dos programas e projetos e na elaboração das políticas estaduais de EA.

Com seus elos, as redes participam ativamente das discussões e da construção das políticas públicas de EA e, em parceria com instituiçôes representativas dos vários segmentos da sociedade, têm contribuído em ações governamentais voltadas ao enraizamento da EA no Brasil. Entre essas ações destacam-se a organização das conferências municipais, regionais, estaduais e nacionais de Meio Ambiente e implantação dos "Com Vidas" e das "Agendas 21".

No entanto, as redes têm discutido sobre a necessidade de cultivar a autonomia e exercer a análise crítica das políticas públicas federal, estadual e municipal, sem estabelecer uma relação de subordinação ao governo, o que, em última análise, poderia comprometer suas próprias ações para implementar estas políticas.

Nesse sentido, a organização das redes de EA pode ser uma alternativa diferenciada e promissora de gestão e organização social, e de parceiras no processo de implementação das políticas públicas, principalmente se considerarmos que a crise ambiental civilizatória (Leff, 
2001) e as lutas pelos direitos humanos confirmam o empobrecimento de grandes parcelas da população mundial, revelam o fracasso da racionalidade econômica que preside o modelo de desenvolvimento em vigor e justificam a busca pacífica de outra estrutura econômica, relacional e cultural entre pessoas e grupos.

Da educação popular à educação ambiental popular: contribuições dos movimentos sociais

Além de discutirmos a temática da expansão da EA nas universidades e os avanços nas políticas públicas, articulando-as com as redes, é necessário também refletir acerca da importância de avançarmos em alguns aspectos relativos a uma educação ambiental popular (Figueiredo, 2003). Isso implica uma práxis de pesquisa-intervenção que, na compreensão deste autor, fundamenta-se numa epistemologia eminentemente dialogal, crítica, intercultural e constituída de modo parceiro e que interage com uma metodologia igualmente fundamentada.

Nesse entendimento, uma educação ambiental crítica (Carvalho, 2001; Figueiredo, 2003, 2007a, 2007b; Guimarães, 1995, 2000; Loureiro, 2004) é um avanço indispensável nesse campo de nossos estudos acerca da EA. Isso carrega em si uma exigência de que não podemos ter uma atitude ingênua ao imaginar que tratar de uma educação ambiental crítica implica uma consequência mecânica e linear de que esta abordagem crítica considere os saberes populares e que, ao dialogar com estes saberes, se reconheçam e valorizem devidamente estes, de modo tal que esses diálogos entre saberes sejam efetivamente os eixos de apoio indispensáveis nesta tessitura de projetos ambientais condizentes e sustentáveis.

Por esse aspecto, a reflexão acerca da EA no contexto dos movimentos sociais impõe como contingência a consolidação do diálogo entre saberes, entre diferentes autores/autoras sociais, entre culturas. Por isso mesmo, não podemos prescindir de Paulo Freire (1983, 1992, 1994, 1996) e de sua proposta dialógica para a educação ambiental popular, que é a EA pertinente neste estudo.

Desde esse alicerce, podemos configurar uma teia epistemológica que contemple os movimentos sociais, em sua especificidade de movimento popular no caminho de suas demandas mais urgentes, que não são poucas, neste início de século. 
Ao destacar alguns aportes freireanos, elencamos principalmente a dimensão política da educação que ele marca como essencial. Além disso, pelo fato de potencializar a voz dos oprimidos, constitui, com os movimentos populares, propostas de práxis social transformadora. Não podemos desconhecer estudos formulados acerca dos movimentos sociais que trouxeram um conjunto de elementos indispensáveis para tratarmos dessa temática ainda incipiente no corpus de pesquisa em EA no Brasil (Scherer-Warren, 2006; Gohn, 1995, 2002). Isto se considerarmos como grandes espaços de divulgação atuais as reuniōes anuais do GT-22, da Associação Nacional de Pós-Graduação e Pesquisa em Educação (ANPed) e os Encontros de Pesquisa em Educação Ambiental (EPEAs), realizados bianualmente em São Paulo, pela UFSCAR, UNESP de Rio Claro e USP de Ribeirão Preto.

Como consequência, podemos perceber a relevância de inserirmos esta chamada aos pesquisadores e pesquisadoras de nosso Brasil para que possamos maturar mais esta interface, conectando adequadamente educação ambiental e movimentos sociais. Afinal, não podemos esquecer que esta é uma das importantes áreas de divulgação e consolidação de políticas potencializadoras de autênticas e efetivas transformações sociais.

Com este intuito no horizonte, é em Freire (1983) que verificamos, por exemplo, um contributo de extrema importância quando ele apresenta-nos uma Teoria Dialógica da Ação, que nos permite reconhecer esta interligação entre educação e movimentos populares. Com esta teoriz-Ação freireana, temos como densificar leituras acerca da relação desejável e pertinente entre educação ambiental e movimentos sociais, no contexto da pesquisa e da intervenção social transformadora.

Para compreendermos um pouco a proposta, apresentamos alguns dos seus aspectos característicos. A proposta de Freire se consubstancia em quatro pontos: colaborar, contrapondo-se a conquistar; unir para libertar, para evitar a estratégia de dividir para dominar; organização dos grupos, opondo-se aos processos de manipulação; síntese cultural, que tematiza a invasão cultural tão ao gosto dos opressores (Freire, 1983).

Nesse bojo teórico-prático indissociável que nos contempla Freire, vamos trilhando e abrindo uma trilha. Vamos costurando e tecendo um bordado que potencializa um avanço saudável na direção de "movimentos" sociais que se alinham numa outra lógica. 
Não podemos esquecer que, neste artigo, o lugar de expressão está restrito aos limites espaciais da publicação. Entretanto, optamos por sinalizar, mapear alguns fatores, elementos e conjuntos que permitirão a outros/as pesquisadores/as investirem neste campo.

Entre outros tópicos que precisam de uma chamada, enfatizamos as questôes acerca da mobilização popular, organização de grupos autônomos, colaborativos, unificados em torno de processos criadores e potencializadores de práxis social transformadora. Ao refletirmos acerca desse tema dobradiça (Freire, 1983), caminhamos na direção do destaque necessário que deduzimos dos estudos de Paulo Freire, nos quais constatamos a indispensabilidade quanto ao grupo-autor/autor-grupo, numa reinterpretação daquilo que Guattari e Rolnik (1986) chamam de grupo-sujeito. No trato desse aspecto, vamos caracterizar o que diferencia o grupo-sujeito do grupo-autor e, em seguida, avançar na direção da essencialidade de integrar dialeticamente o grupo-autor com o autorgrupo, de modo que se articulem permanentemente.

No que se refere ao primeiro aspecto, cabe buscar a compreensão do sentido que se dá ao "sujeito". Se recorrermos ao dicionário (Ferreira, 1999), sujeito significa, entre outras coisas, súdito, escravizado, cativo, subjugado, obrigado, constrangido, adstrito, o que se sujeita à vontade dos outros; obediente, dócil, dependente, submetido, exposto, passível. Certamente, não é isso que pretendemos para aqueles que compõem os movimentos sociais, que se movem articuladamente na tentativa de superação desse quadro de opressão e subjugação social imposto pelas elites, pelos que detêm o poder no sistema social no qual estamos inseridos. Então, preferirmos optar por autor social, que alarga também a idéia de ator (aquele que age segundo um papel que lhe designam).

A valorização das diferenças, dos diferentes, gera potência inigualável, pois instiga a afetividade no trato dos saberes singulares e recomposição contínua do saber grupal, na forja do saber parceiro desse grupo-autor de sua própria história. Percursos de desejos se entrecruzam com trajetos de significação, que lhes facultam o ser-mais em si e no movimento social.

\section{Concluindo}

$\mathrm{O}$ que apresentamos nesse artigo pretendeu mostrar como a educação ambiental vem-se consolidando politicamente no Brasil, 
Hedy S. Vasconcellos, Maria L. Spazziani, Antonio F. Guerra \& João B. Figueiredo

tornando-se visível no campo universitário e ampliando seus horizontes de sentido e de tessitura no bordado de sua própria capacidade de expansão e intervenção social transformadora. Isto, embora ainda esteja longe da concretização da utopia perseguida pelos educadores ambientais.

Recebido em janeiro de 2008 e aprovado em outubro de 2008.

\section{Notas}

1. Trata-se de realizar mudanças no sistema educativo que incluam "inovaçôes conceituais, metodológicas e atitudinais, mas também estruturais e organizacionais, que permitam um enfoque interdisciplinar no currículo, que facilite um planejamento global de objetivos e conteúdos, que se aproxime da compreensão da complexidade e da visão planetária (...) que facilitem a descentralização e a flexibilidade do currículo necessárias para adaptar-se ao entorno e dar respostas as suas inquietudes” (Gonzáles Muñoz, 1996, p. 37).

2. Ver Parecer n. 819/85 do MEC e Parecer n. 226/87 do CFE. Em 1979, o Departamento do Ensino Médio/ MEC e a Companhia de Tecnologia e Saneamento Ambiental da Secretaria de Meio Ambiente de São Paulo (CETESB) publicam o documento "Ecologia - uma proposta para o ensino de $1^{\circ}$ e $2^{\circ}$ graus".

3. Criado em 1989 pela junção da SEMA, SUDEPE, SUDEHVEA e IBDF, nele funciona a Divisão de Educação Ambiental.

4. A Rede Brasileira de Educação Ambiental (REBEA), gestada no âmbito do Fórum Global das ONGs, em 1992, "enreda” mais de 45 redes estaduais, regionais, intermunicipais, municipais, nacionais e internacionais e redes temáticas.

\section{Referências}

ALVES, L.S. A educação ambiental e a pós-graduação: um olhar para a produção discente. 2006. 297f. Dissertação (Mestrado) - Departamento de Educação, Pontifícia Universidade Católica do Rio de Janeiro, Rio de Janeiro.

BOSCHI, R.R. A arte da associação: política de base e democracia no Brasil. São Paulo: Vértice, 1987.

BRASIL. Constituição (1988). Constituição da República Federativa do Brasil. Brasília, DF: Senado Federal, 1988.

BRASIL. Lei n. 5.540, de 29 de novembro de 1968. Fixa normas de organização e funcionamento do ensino superior e sua articulação com a escola média, e dá outras providências. Diário Oficial [da] República 
Federativa do Brasil, Brasília, 29 de novembro de 1968. Retificada no D.O. de 3 de dezembro de 1968. Brasília, DF: Congresso Nacional, 1968.

BRASIL. Lei n. 9.795, de 27 de abril de 1999. Dispõe sobre a educação ambiental, institui a Política Nacional de Educação Ambiental e dá outras providências. Diário Oficial da União, Brasília, DF, 28/04/1999.

BRASIL. Ministério da Educação. Secretaria de Educação Fundamental. Parâmetros curriculares nacionais: apresentação dos temas transversais. Brasília, DF: MEC/SEF, 1997.

BRASIL. Ministério do Meio Ambiente. Diretoria de Educação Ambiental. Programa Nacional de Educação Ambiental - PRONEA. 3. ed. Brasília, DF: MMA/MEC, 2005.

BRASIL. Órgão Gestor da Política de Educação Ambiental. Portfólio. Brasília, DF, 2006. (Documentos técnicos, n. 7).

CAPRA, F. A teia da vida. São Paulo: Cultrix, 1996.

CARVALHO, I.C.M. A invenção ecológica: narrativas e trajetórias da educação ambiental no Brasil. Porto Alegre: Universitária; UfRGS, 2001.

CASTRO, R.S.; SPAZZIANI, M.L.; PEDROSA, E. Universidade, meio ambiente e parâmetros curriculares nacionais. In: CASTRO, R.S.; Layargues, P.P.; Loureiro, C.F.S. (Org.). Sociedade e meio ambiente: a educação ambiental em debate. 3. ed. São Paulo: Cortez, 2002. p. 157-180.

DIAS, G.F. Educação ambiental: princípios e práticas. 9. ed. São Paulo: Gaia, 2004.

FERREIRA, A.B.H. Novo dicionário Aurélio: século XXI. Rio de Janeiro: Nova Fronteira, 1999. (CD-ROM).

FIGUEIREDO, J. Educação ambiental dialógica e representaçôes sociais da água em cultura sertaneja nordestina: uma contribuição à consciência ambiental em Irauçuba-CE (Brasil). 2003. Tese (Doutorado) Universidade Federal de São Carlos, São Carlos.

FIGUEIREDO, J. Educação ambiental dialógica: as contribuições de Paulo Freire e da cultura sertaneja nordestina. Fortaleza: UFC, 2007a. (Diálogos intempestivos, 43). 
Hedy S. Vasconcellos, Maria L. Spazziani, Antonio F. Guerra \& João B. Figueiredo

FIGUEIREDO, J. Educação ambiental e o educador em formação numa perspectiva eco-relacional. In: REUNIÃO ANUAL DA ANPEd. 30., 2007, Caxambu. Anais... Rio de Janeiro: ANPed, 2007b.

FÓRUM Internacional de Organizaçôes Não-Governamentais e Movimentos Sociais. Tratado de Educação Ambiental para sociedades sustentáveis e responsabilidade global. In: TRATADO das ONGs; aprovado no Fórum Internacional de Organizações Não-Governamentais e Movimentos Sociais, no Âmbito do Fórum Global - ECO-92. Rio de Janeiro: Eco, 1992, p. 193-196.

FREIRE, P. Pedagogia do oprimido. 13. ed. Rio de Janeiro: Paz \& Terra, 1983.

FREIRE, P. Extensão ou comunicação? Trad. Rosisca D. de Oliveira. 10. ed. Rio de Janeiro: Paz \& Terra, 1992.

FREIRE, P. Pedagogia da esperança: um reencontro com a pedagogia do oprimido. 3. ed. Rio de Janeiro: Paz \& Terra, 1994.

FREIRE, P. Pedagogia da autonomia: saberes necessários à prática educativa. São Paulo: Paz \& Terra, 1996.

GOHN, M.G.M. História dos movimentos e lutas sociais. São Paulo: Loyola, 1995. v.1.

GOHN, M.G.M. Movimentos sociais e educação. 5. ed. São Paulo: Cortez, 2002. v.1, p. 128.

GONZÁLEZ MUÑOZ, M.C. Principales tendencias y modelos de la Educación Ambiental en el sistema escolar. Revista Iberoamericana de Educación, Madrid, n. 11, p. 13-74, 1996.

GUATTARI, F.; ROLNIK, S. Cartografia do desejo. 2. ed. Petrópolis: Vozes, 1986.

GUERRA, A.F.S.; FIGUEIREDO, M.L.; JUSTEN, L.M. Tecendo a rede de educadores ambientais da região Sul. Revista Brasileira de Educação Ambiental, Brasília, DF, v. 1, n. 0, p. 99-107, 2004.

GUERRA, A.F.S.; FIGUEIREDO, M.L.; JUSTEN, L.M. As redes no espelho: conceitos e práticas da cultura de redes de educação 
ambiental. In: Guerra, A.F.S.; TAgLieber, J.E. Educação ambiental: fundamentos práticas e desafios. Itajaí: UNIVALI, 2007. p. 107-123.

GUIMARÃES, M. A dimensão ambiental na educação. Campinas: Papirus, 1995.

GUIMARÃES, M. Educação ambiental: no consenso um embate? Campinas: Papirus, 2000.

INOJOSA, R.M. Redes de compromisso social. Revista de Administração Pública, Rio de Janeiro, v. 33, n. 5, p.115-141, set./out. 1999.

LEFF, E. Epistemologia ambiental. São Paulo: Cortez, 2001.

LIMA, A. Do universo das redes as redes de educação ambiental: potencialidades e limitaçôes da Rede Sul Brasileira de Educação Ambiental - REASUL, Rio Grande-RS. 2006. 161f. Dissertação (Mestrado em Educação Ambiental) - Programa de Pós-Graduação em Educação Ambiental, Fundação Universidade Federal do Rio Grande, Rio Grande, RS.

LOUREIRO, C.F.B. Trajetória e fundamentos da educação ambiental. São Paulo: Cortez, 2004.

LOUREIRO, C.F.B.; LAYRARGUES, P.P.; CASTRO, R.S. (Org.). Sociedade e meio ambiente: a educação ambiental em debate. São Paulo: Cortez, 2000.

MARTINHO, C. (Coord.). Redes: uma introdução às dinâmicas da conectividade e da auto-organização. Brasília, DF: WWF-Brasil, 2004.

MEGID NETO, J. (Coord.). O ensino de ciências no Brasil: catálogo analítico de teses e dissertaçôes 1972-1995. Campinas: FE/UniCAMP, 1998.

SCHERER-WARREN, I. Cidadania sem fronteiras: ações coletivas na era da globalização. São Paulo: Hucitec, 1999.

SCHERER-WARREN, I. Das mobilizações às redes de movimentos sociais. Sociedade \& Estado, Brasília, DF, v. 21, p.109-130, 2006.

VASCONCELLOS, H.S.R. Extensão universitária e educação em comunidade periférica do Rio de Janeiro. 1991. 309f. Tese (Doutorado) - 
Hedy S. Vasconcellos, Maria L. Spazziani, Antonio F. Guerra \& João B. Figueiredo

Faculdade de Educação, Universidade Federal do Rio de Janeiro, Rio de Janeiro.

VASCONCELLOS, H.S.R. (Coord.). A educação ambiental na universidade: um banco de dados. Rio de Janeiro: Departamento de Educação; PUC-RIO, 1999. 